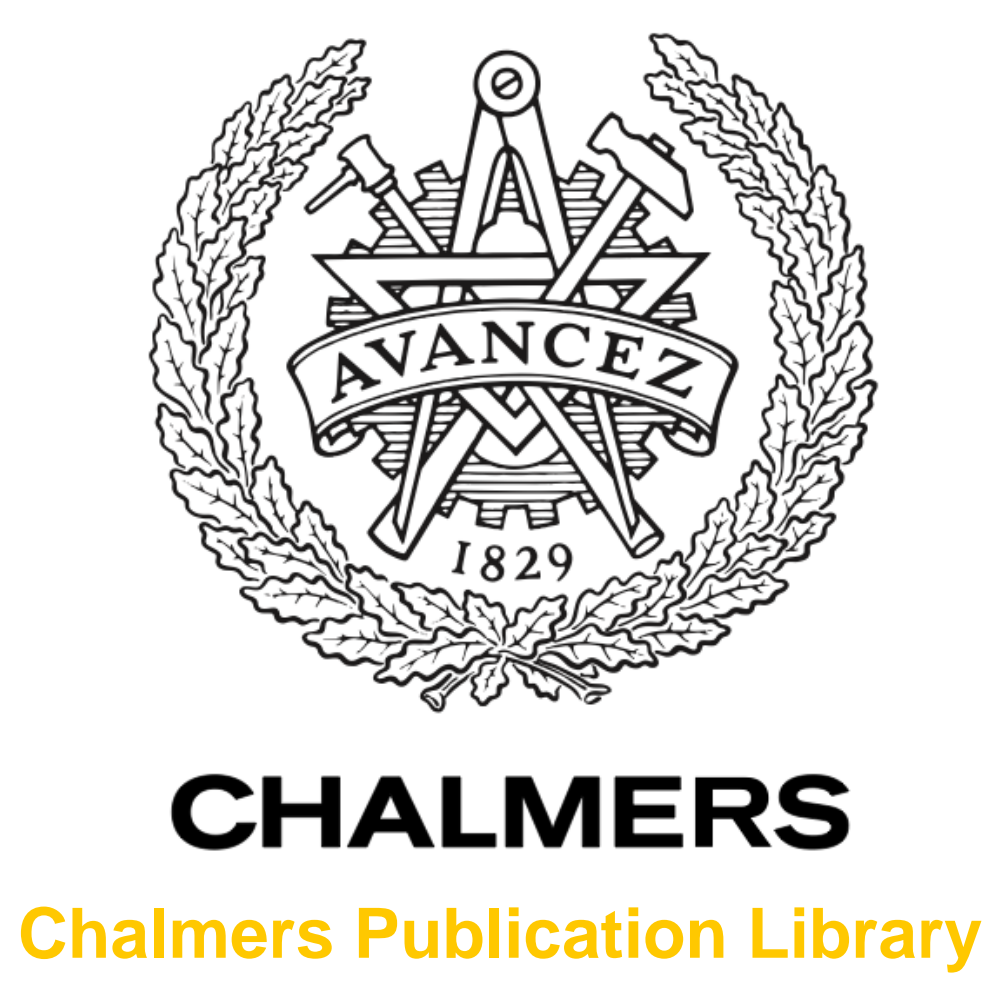

\title{
Performance of a passive sampler for the determination of time averaged concentrations of nitrate and phosphate in water
}

This document has been downloaded from Chalmers Publication Library $(\mathrm{CPL})$. It is the author's version of a work that was accepted for publication in:

Environmental Science: Processes \& Impacts (ISSN: 2050-7887)

Citation for the published paper:

Knutsson, J. ; Rauch, S. ; Morrison, G. (2013) "Performance of a passive sampler for the determination of time averaged concentrations of nitrate and phosphate in water".

Environmental Science: Processes \& Impacts

Downloaded from: http://publications.lib.chalmers.se/publication/175728

Notice: Changes introduced as a result of publishing processes such as copy-editing and formatting may not be reflected in this document. For a definitive version of this work, please refer to the published source. Please note that access to the published version might require a subscription. 


\section{Performance of a passive sampler for the determination of time averaged concentrations of nitrate and phosphate in water}

\author{
${ }_{5}$ Jesper Knutsson*a, Sebastien Rauch ${ }^{\text {a }}$, Gregory M. \\ Morrison $^{\mathrm{a}}$ \\ ${ }^{a}$ Water Environment Technology, Civil and \\ Environmental Engineering, Chalmers \\ University of Technology, SE-412 96 Göteborg, \\ ${ }_{10}$ Sweden \\ ${ }^{*}$ Corresponding author, \\ jesper.knutsson@chalmers.se
}

\begin{abstract}
A passive sampler device for the kinetic accumulation of nitrate ${ }_{15}\left(\mathrm{NO}_{3}{ }^{-}\right)$and phosphate $\left(\mathrm{HPO}_{4}{ }^{2-}\right)$ in water was developed and calibrated. The sampler incorporates an ion exchange disk as receiving phase and selectively collects nitrate and phosphate at sampling rates of $197 \pm 43$ and $75 \pm 12 \mathrm{~mL} \mathrm{day}^{-1}$, respectively. Minimum exposure times under nutrient rich and nutrient poor 20 conditions were estimated to be 3 and 27 days respectively for phosphate and 1 and 7 days respectively for nitrate. The influence of the environmental variables $\mathrm{pH}(5-9)$, temperature $\left(7-21^{\circ} \mathrm{C}\right.$ ) and turbulence (50-400 rpm) on sampling rates investigated. Temperature was found to have a significant influence on uptake 25 rates for both anions, while $\mathrm{pH}$ influenced phosphate only. Water turbulence did not influence the uptake rates under the studied conditions. A series of field studies was conducted at a municipal wastewater treatment plant. Results for the passive sampler were lower than concentrations obtained using conventional 30 measurement methods, due to methodological differences, and biofouling was found to affect the results for sampling periods over 3 days. This study shows that passive sampling can be used to monitor nitrate and phosphate concentrations in aqueous media. The approach provides an interesting alternative to grab

35 sampling as it yields time-averaged concentrations of the analytes.
\end{abstract}

Keywords: nutrients, monitoring, nitrate, phosphate, passive sampling, wastewater

\section{Introduction}

${ }_{40}$ Species of phosphate and nitrate have a fundamental role for biological production in aquatic ecosystems. In pristine freshwater bodies phosphorus is often the limiting nutrient, and the excessive release of both phosphorus and nitrogen species from agriculture and domestic wastewater can lead to the 45 eutrophication of lakes and watercourses ${ }^{1}$.
Efforts to achieve a good water quality status, such as the EU Water Framework Directive (WFD, Directive 2000/60/EC), need to be supported by cost-effective monitoring of nitrate and phosphate. Traditionally there has been a choice between manual 50 grab sampling or automated sampling systems followed by laboratory analysis, or continuous in-situ monitoring using for example on-line probes. Grab sampling followed by laboratory analysis remains the preferred option, despite the lack of representativeness of the sampling, as well as reported issues 55 with the commonly used molybdenum blue method ${ }^{2}$.

Passive sampling provides an interesting alternative for (line monitoring chemicals in aquatic systems. The method is based on the diffusion of the analyte between two compartments with different chemical potential, where one compartment acts as a 60 collecting, or receiving, phase and the other compartment consists of the bulk water3, 4. Passive samplers have a number of potential advantages over conventional sampling techniques for the long term monitoring of levels of pollutants in water, including the capability of providing a time weighted average 65 over a prolonged measurement period and catching potentially significant pollution spikes that would otherwise go undetected 5 , as well as preconcentration, speciation and preservation of analytes 6. Passive samplers have been evaluated for their applicability to the monitoring requirements of the WFD 7, both 70 for organic and metal pollutants 5, 8, 9. However, only a limited research literature has addressed the passive sampling of nutrients, and most of the existing publications primarily address phosphate 10, 11 although recently a novel passive sampler was applied to both NO3 and P 12. The most common receiving 75 phases are based on ferrihydrite 10, 13-15, but zirconium oxide 16 and titanium dioxide 11 have also been used.

This paper describes the performance of a passive sampler comprising an anion exchange resin as receiving phase for the insitu sampling of nitrate and phosphate. The sampling device is 80 based on Chemcatcher, a passive sampler with demonstrated applicability to the monitoring of metals 5,17 and organic compounds ${ }^{18,19}$ in aqueous media. The influence of selected environmental variables (temperature, $\mathrm{pH}$ and turbulence) on the calibration parameters for nitrate and phosphate is presented and 85 the selectivity of the method is assessed by comparing different sampling and analytical methods. Nitrate and phosphate 
monitoring in municipal wastewater is presented as an example of an application.

\section{Experimental}

\section{${ }_{90}$ Chemcatcher passive sampler}

A schematic representation of the design of the Chemcatcher passive sampler is shown in Figure 1. The sampler comprises a housing with five parts made of Teflon (illustrated as numbers 1,2,3 and 6 in figure 1), a diffusion limiting membrane (number 955 ) and an ion-exchange receiving disk (number 4) placed in the sampler housing.
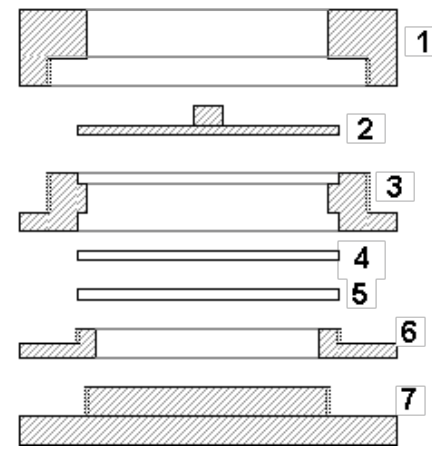

Figure 1. Exploded diagram of the passive sampler device in crosssection. 1, 3, 6 sampler housing, 2. disk support, 4. Receiving $47 \mathrm{~mm}$ 100 disk, 5. Diffusion limiting membrane, 7. transport lid.

Based on experience from previous applications ${ }^{5,9,20}$, a Sartorius (Sartorius AG, Germany) $47 \mathrm{~mm}$ cellulose acetate filter with nominal pore size $0.45 \mu \mathrm{m}$ was used as the diffusion limiting membrane. The receiving phase, an Empore ${ }^{\mathrm{TM}}$ Anion SR 105 extraction disk (diameter $47 \mathrm{~mm}$ ), was selected because of the affinity of the functional group of the sorbent to both nitrate and phosphate $^{21}$.

\section{Sampling principle}

The working principle of the Chemcatcher passive sampler is 110 based on Fick's first law of diffusion as the affinity of the sorbent for the analyte is sufficiently high to maintain a zero concentration at the surface of the receiving phase (Equation 1) 22 .

$$
m=-P \frac{d C}{d x} \quad \text { Equation } 1
$$

where $\mathrm{m}$ is the rate of transfer $\left(\mathrm{g} \mathrm{s}^{-1}\right)$ of analyte across the 115 diffusion limiting membrane, $\mathrm{P}$ is the permeability coefficient $\left(\mathrm{cm}^{4} \mathrm{~s}^{-1}\right)$ and $\frac{d C}{d x}$ represents the concentration gradient $\left(\mathrm{g} \mathrm{cm}^{-4}\right)$ of the analyte across the diffusion path $\mathrm{x}(\mathrm{cm})^{17,22}$.

When the device has reached a steady state, a constant sampling rate can be assumed and the concentration of a chemical in the 120 organic phase can then be assumed to be directly proportional to the product of the concentration in the surrounding aqueous medium $\mathrm{C}_{\mathrm{b}}$ and the exposure time t. For practical applications, the mass of the accumulated analyte can be calculated following Equation 2.

$$
m-m_{0}=R_{s} \cdot c_{b} \cdot t \quad \text { Equation } 2
$$

125 where $R_{s}\left(\mathrm{Lh}^{-1}\right)$ is the sampling rate and $c_{b}\left(\mathrm{~g} \mathrm{~L}^{-1}\right)$ is the bulk concentration of the analyte, $\mathrm{m}_{0}$ is the analyte mass of a procedural blank and $t(\mathrm{~h})$ is the exposure time.

It follows that it is also possible to determine the sampling rate $\left(R_{s}\right)$ for any analyte from a regression of the mass $\left(\mathrm{m}-\mathrm{m}_{\mathrm{o}}\right)$ 130 accumulated in the receiving phase over a given time $(t)$ of exposure to a constant external concentration (c) of the analyte as well as the time-weighted average concentration in the bulk phase (Equation 3).

$$
c_{b}=\frac{\left(m-m_{0}\right)}{R_{s} \cdot t} \quad \text { Equation } 3
$$




\section{Disk activation and elution}

135 The Anion-SR disks (the receiving phase) were placed in a vacuum filtering system and then conditioned by addition of HPLC-grade methanol (15 mL) allowing the disk to soak for 60 seconds. Subesquently vacuum was applied until methanol was almost drawn through the disk, at which point 2 aliquots of 15 $140 \mathrm{~mL}$ de-ionized water (grade I reagent water, $>18 \mathrm{M} \Omega$ ) were added to wash the receiving disk.

The conditioned Anion-SR disk (no. 4 in figure 1) was placed over the supporting disk (2), followed by a diffusion limiting membrane (5) was placed over the conditioned disk. The 145 supporting disk was then placed on the sampler body (1) and finally the lid (3) was screwed tight. The prepared sampler was left in de-ionized water until deployed.

After exposure the extraction of the analyte from the disks was performed using a glass vacuum filtration equipment by 150 subsequently adding 2 aliquots $(25 \mathrm{~mL})$ of $0.5 \mathrm{M} \mathrm{HCl}$, letting the acid pass slowly through the disk during 10 seconds. Trace analysis quality (Scharlau, Spain) $\mathrm{HCl}$ were used and the extraction procedure consistently yielded analyte recoveries above $90 \%$.

\section{Analytical techniques}

Nitrate concentrations in passive sampler eluents were determined on a Waters HPLC system (Waters Corporation, USA) fitted with a Waters Anion HR column (4.6 x 75 mm) and UV-detection at $220 \mathrm{~nm}$. Limit of quantification (LOQ) were 160 determined to be $50 \mu \mathrm{g} \mathrm{L}{ }^{-1}$.

Phosphate concentrations in passive sampler eluents were determined as phosphorus on an Elan 6000 ICP-MS (Perkin Elmer, Canada) using cross-flow nebulization. It is assumed that all phosphorous collected by the passive sampler is in the form of 165 phosphate; comparison of ICP-MS and ion chromatography measurements confirmed this assumption, as described below. The instrument was optimised daily to reach at least $400 \mathrm{k}$ cps for a 10ppb indium solution with oxide levels $(\mathrm{CeO} / \mathrm{Ce})$ and doubly charged ions $\left(\mathrm{Ba}^{++} / \mathrm{Ba}^{+}\right)$below 3\%. Rhodium $\left(10 \mu \mathrm{g} \mathrm{L}^{-1}\right)$ was 170 used as internal standard. LOD and LOQ were $5 \mu \mathrm{g} \mathrm{L}^{-1}$ and $15 \mu \mathrm{g}$ $\mathrm{L}^{-1}$, respectively.
In the validation experiment nitrate and phoshate concentrations in wastewater were determined using a Dionex ICS-900 ion chromatograph. Eluent was prepared from commercial stock 175 solution by diluting with laboratory grade I water. Samples were filtered through $0.45 \mu \mathrm{m}$ CA membrane filter (Sartorius) using a syringe fitted with a $25 \mathrm{~mm}$ filter holder. Samples were stored in a refrigerator prior to the analysis, which was carried out within 5 days of the completion of the experiment..

180 The results from the water treatment plant laboratory were obtained using a commercial quick-test colorimetric method based on the reaction of the $\mathrm{HPO}_{4}{ }^{2-}$ with molybdenum acid (molybdenum blue reactive phosphate), followed by flow injection analysis according to EN ISO 13395:1996 (nitrate). 185 Analyses were performed daily on pooled samples.

Calibration standards for the determination of nitrate $(0.1-10 \mathrm{mg}$ $\mathrm{L}^{-1}$ ) and phosphate (0.5-5 $\mathrm{mg} \mathrm{L}^{-1}$ ) were prepared from potassium nitrate salt (Merck, Germany; p.a. quality) and potassium dihydrogen phosphate (Merck, Germany; p.a. quality), 190 respectively. The water used for dilution of stock solution and samples was laboratory grade I water (>18 MOhm) obtained from a Millipore Milli-Q water system with deionized feed water.

\section{Experimental set-up}

\section{Calibration of the samplers}

195 Calibration of the passive samplers was performed in a $10 \mathrm{~L}$ flow-through exposure tank made from polyethene. Each calibration consisted of 14 exposed samplers, where one device was removed for analysis at $24 \mathrm{~h}$ intervals (with the exception of two days when no samplers were removed) over a period of 16 200 days. Nominal analyte levels were $2 \mathrm{mg} \mathrm{L}^{-1}$ for nitrate and $1 \mathrm{mg}$ $\mathrm{L}^{-1}$ for phosphate.

The steady concentration of the analytes was maintained using a Heidolph PD 5001 peristaltic pump with a continuous flowthrough $\left(0.5 \mathrm{~mL} \mathrm{~min}^{-1}\right)$ of stock solution. The chosen temperature $205\left(14^{\circ} \mathrm{C}\right)$ was maintained using a thermostatically controlled water bath and the $\mathrm{pH}(7.0 \pm 0.2)$ adjusted by the addition of $1 \mathrm{M} \mathrm{NaOH}$ to the stock solution in the reservoir. New stock solutions were prepared every 7 days and the $\mathrm{pH}$ in the exposure tank was monitored daily. An overhead stirrer (IKA RW 20 DZM) with a 210 Stainless steel propeller rotated at $200 \mathrm{rpm}$ was used to provide 3 
controlled turbulence. Three sampler blanks were measured and did not give any detectable amounts of either nitrate or phosphate.

\section{Laboratory deployment of samplers}

215 Laboratory exposures were performed to examine the effect of environmental variables on the uptake rates of the sampler, A three-way orthogonal factorial experimental design was chosen to allow independent evaluation of the parameters ${ }^{23}$. Temperature (7, 14, 21 $\left.{ }^{\circ} \mathrm{C}\right)$, turbulence (propeller speed 50, 200, $400 \mathrm{rpm}$ ) and ${ }_{220} \mathrm{pH}(5,7,9)$ were varied in a reduced set of experiments. Over a period of 16 days, 15 passive samplers were exposed in a constant concentration flow-through exposure tank, immersed in an outer thermostatically controlled water bath, and with overhead stirring in the exposure tank. The nominal bulk 225 concentration of $\mathrm{NO}_{3}{ }^{-}$and $\mathrm{HPO}_{4}{ }^{2-}$ was kept at $2.0 \mathrm{mg} \mathrm{L}^{-1}$ and 1.0 $\mathrm{mg} \mathrm{L}^{-1}$ respectively by constant replenishment $\left(0.5 \mathrm{~mL} \mathrm{~min}^{-1}\right)$ from a stock solution reservoir. The $\mathrm{pH}$ was adjusted batch-wise in the water reservoir through drop-wise addition of $1 \mathrm{M} \mathrm{NaOH}$. The passive samplers were collected after exposure and the 230 accumulated amounts of nitrate and phosphate were determined using the methodology described in the analytical section.

\section{Selectivity experiment}

In order to assess the passive sampler selectivity a validation study was conducted in the laboratory using effluent water 235 collected at the waste water treatment plant (WWTP). A total of nine passive samplers were exposed in a 25 liter tank for three days. The whole volume was thoroughly stirred using an overhead propeller stirrer and the temperature was kept at $20^{\circ} \mathrm{C}$ throughout the experiment.

240 Three passive samplers were removed from the tank at intervals of approximately 24 hours. The receiving disks were then extracted and the extract was analyzed for nitrate and phosphate using ion chromatography and ICP-MS respectively.

Samples of the bulk water from the tank were also collected and 245 analyzed for nitrate and phosphate concentrations using colorimetry (Hach Method 10209 for Reactive Phosphorous), ion chromatography and ICP-MS to determine speciation and total concentration of $\mathrm{N}$ and $\mathrm{P}$ species.

\section{Field deployment of the samplers}

250 The Ryaverket municipal wastewater treatment plant in Gothenburg was chosen as a test site for device deployment. Three replicate samplers were prepared and conditioned and transported to the deployment site in acid rinsed glass containers filled with reagent water. On site samplers attached to a $50 \mathrm{~cm}$ 255 wooden holder, were fixed in place by a steel wire. The device was anchored in a railing immediately above the outdoor sampling site in the secondary settling pond within the plant compound. The deployed samplers were exposed for periods of three days and one week respectively, in open secondary settling 260 tanks in three separate trials at about 0.5 meters depth and at turbulence levels estimated to $<0.5 \mathrm{~cm} \mathrm{~s}^{-1}$. The temperature and $\mathrm{pH}$ remained fairly stable throughout the sampling period and remained between $18-20^{\circ} \mathrm{C}$ and 6.4-7.1 respectively.

\section{Results and discussion}

\section{Determination of sampling rates}

Passive sampling devices are used to obtain the time-averaged concentration of an analyte in a water body ${ }^{24-26}$. In order to obtain correct estimates of the pollutant concentration the sampler has to be undersaturated and remain in the linear region 270 throughout the exposure period ${ }^{27}$. A successful choice of a receiving disk is therefore a disk with high sorption capacity yet low sampling rate for the sampled analyte ${ }^{27}$. Linear accumulation for both nitrate and phosphate was observed in the calibration experiments for Chemcatcher in laboratory conditions for the 16 275 day period (Figure 4). The observed spread of the data points from the straight line was attributed to variance in the chromatographic determinations and variations in analyte recovery.

From the uptake curves, the sampling rates $\left(R_{s}\right)$ for the two 280 analytes of interest were determined as $193 \pm 16 \mathrm{~mL}^{-1 a y}{ }^{-1}$ and 83 $\pm 17 \mathrm{~mL} \mathrm{day}^{-1}$ (95\% confidence interval) for nitrate and phosphate, respectively. The difference in sampling rates agrees reasonably well with the difference in diffusion coefficients for $\mathrm{NO}_{3}^{-}$and $\mathrm{H}_{2} \mathrm{PO}_{4}^{-}, 1.7 \times 10^{-9} \mathrm{~m}^{2} \mathrm{~s}^{-1}$ and $5.3 \times 10^{-109} \mathrm{~m}^{2} \mathrm{~s}^{-1}$ in 285 water, respectively ${ }^{28}$. 

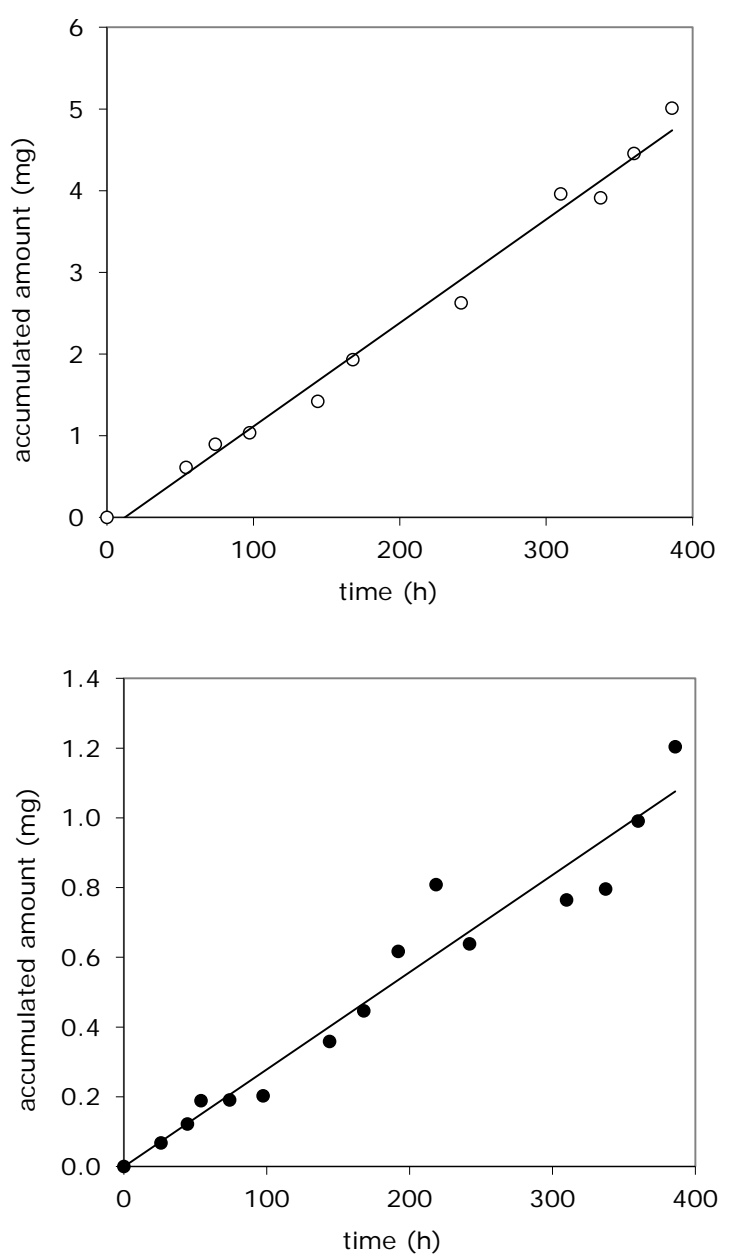

Figure 2. Calibration curves for nitrate (top) and phosphate (bottom) at $\mathrm{pH} 7.0,14^{\circ} \mathrm{C}, 200 \mathrm{rpm}$ and analyte exposure levels $2 \mathrm{mg} \mathrm{L}^{-1}$ nitrate and 1 $290 \mathrm{mg} \mathrm{L}^{-1}$ phosphate, maintained by stock solution flow-through at $0.5 \mathrm{~mL}$ $\mathrm{min}^{-1}$. Three data points in the nitrate curve has been omitted as they were either under the quantification limit or due to peak interference.

\section{Influence of external parameters}

In previous studies performed on Chemcatcher, temperature, $\mathrm{pH}$ 295 and turbulence were the parameters that significantly influenced the uptake rate for metals and organics ${ }^{29,}{ }^{30}$. The effect of variations in temperature, turbulence and $\mathrm{pH}$ on uptake on the passive sampler was assessed for $\mathrm{NO}_{3}{ }^{-}$and $\mathrm{HPO}_{4}{ }^{2-}$ using a previously reported experimental setup ${ }^{31}$. The results were 300 summarized for the different conditions and presented in Table 1.

Table 1. Results for the factor variation experiments showing experiment design with selected factor levels, the average accumulated amount of nitrate and phosphate on the disks and the standard deviations for three replicate sampler $96 \mathrm{~h}$ exposures.

\begin{tabular}{|c|c|c|c|c|c|c|c|}
\hline Trial set & $\mathrm{pH}$ & $\begin{array}{l}\text { temperature } \\
\text { (으) }\end{array}$ & $\begin{array}{l}\text { Turbulence } \\
\text { (rpm) }\end{array}$ & Amount Nitrate (mg) & $\begin{array}{l}\text { Standard } \\
\text { deviation (mg) }\end{array}$ & Amount Phosphate (mg) & $\begin{array}{l}\text { Standard } \\
\text { deviation (mg) }\end{array}$ \\
\hline 1 & 5 & 7 & 50 & 2.86 & 0.52 & 0.71 & 0.03 \\
\hline 2 & 5 & 14 & 200 & 3.75 & 0.56 & 0.99 & 0.20 \\
\hline 3 & 5 & 21 & 400 & 5.05 & 0.57 & 1.31 & 0.05 \\
\hline 4 & 7 & 7 & 200 & 3.05 & 0.37 & 0.98 & 0.14 \\
\hline 5 & 7 & 14 & 400 & 3.95 & 0.86 & 1.57 & 0.22 \\
\hline 6 & 7 & 21 & 50 & 4.65 & 0.73 & 2.00 & 0.16 \\
\hline 7 & 9 & 7 & 400 & 3.00 & 0.53 & 1.58 & 0.46 \\
\hline 8 & 9 & 14 & 50 & 4.06 & 0.17 & 1.57 & 0.35 \\
\hline 9 & 9 & 21 & 200 & 3.96 & 1.41 & 2.01 & 0.12 \\
\hline
\end{tabular}

examine its relationship to the tested variables $(\mathrm{pH}$, temperature

Multivariable analysis was applied to the obtained data to 305 evaluate the influence of the chosen environmental variables on the sampling capacities of the Chemcatcher for the studied nutrients. Analysis of variance (ANOVA) was used to test the difference in uptake rate under different conditions and to
310 and turbulence). All statistical analyses were performed using $\mathrm{R}$ statistical software $^{32}$ (see electronic supplemental information for input files). The correlation analysis performed on the dataset show that temperature and $\mathrm{pH}$ have a statistically significant influence on the uptake rate of $\mathrm{HPO}_{4}{ }^{2-}$ and temperatire for uptake 315 rate of $\mathrm{NO}_{3}{ }^{-}$(the null hypothesis can be rejected on the $99.9 \%$ 
confidence level), while variance attributed to turbulence was very low and therefore was considered to be of small significance for the uptake rate (see Table 2 and Table 3).

Table 2. Result table for Anova analysis of factor variation experimental 320 results for nitrate.

\begin{tabular}{lllll}
\hline & $\begin{array}{l}\text { Degrees of } \\
\text { freedom }\end{array}$ & $\begin{array}{l}\text { Sum of } \\
\text { Squares }\end{array}$ & F value & $\operatorname{Pr}(>\mathrm{F})$ \\
\hline $\mathrm{pH}$ & 1 & 0.199 & 0.41 & 0.52 \\
Temperature & 1 & 11.265 & 23.44 & $6.90 \times 10^{-5}$ \\
Turbulence & 1 & 0.133 & 0.28 & 0.60 \\
\hline Residuals & 23 & 11.051 & & \\
\hline
\end{tabular}

Table 3. Result table for Anova analysis of factor variation experimental results for phosphate.

\begin{tabular}{lllll}
\hline & $\begin{array}{l}\text { Degrees of } \\
\text { freedom }\end{array}$ & $\begin{array}{l}\text { Sum of } \\
\text { Squares }\end{array}$ & F value & $\operatorname{Pr}(>\mathrm{F})$ \\
\hline $\mathrm{pH}$ & 1 & 2.3173 & 35.95 & $4.09 \times 10^{-6}$ \\
Temperature & 1 & 2.1096 & 32.73 & $7.94 \times 10^{-6}$ \\
Turbulence & 1 & 0.0230 & 0.36 & 0.55 \\
\hline Residuals & 23 & 1.4823 & & \\
\hline
\end{tabular}

325 Temperature dependence of the uptake rate has previously been observed for diffusion based passive samplers ${ }^{20,33}$. Its influence is mainly explained through the temperature dependence of the diffusion coefficient and the activation energy of sorption and ion exchange. Here, the increase in temperature led to a slightly 330 higher increase in the case of phosphate, possibly due to the higher activation energy for $\mathrm{H}_{2} \mathrm{PO}_{4}{ }^{-} / \mathrm{Cl}^{-}$exchange than for $\mathrm{NO}_{3}{ }^{-}$ $/ \mathrm{Cl}^{-}$(see Table 3).

The $\mathrm{pH}$ influence on the uptake rates was found to depend on $\mathrm{pH}$ within ranges perceivably found in treated effluents and natural 335 waters, in contrast to what has been observed and reported for passive samplers with a receiving phase based on metal oxide ${ }^{10}$, 11, 16. The importance of $\mathrm{pH}$ in the present study was expected, especially for the phosphates, and can be directly attributed to the $\mathrm{pH}$ dependence of the equilibrium species of phosphate $\left(\mathrm{HPO}_{4}{ }^{2-}\right.$ 340 and $\mathrm{H}_{2} \mathrm{PO}_{4}{ }^{-}$). A higher $\mathrm{pH}$ is expected to result in an increased occurrence of $\mathrm{HPO}_{4}^{2-}$ and an increased accumulation of phosphorus, considering the higher affinity of $\mathrm{HPO}_{4}{ }^{2-}$ for the receiving membrane compared to $\mathrm{H}_{2} \mathrm{PO}_{4}^{-}$. This was confimred by the results shown in Figure 3, as an increase in $\mathrm{pH}$ leads to a 345 significant increase in phosphate sampling rate. No statistically significant influence of the $\mathrm{pH}$ was observed for $\mathrm{NO}_{3}{ }^{-}$ accumulation.
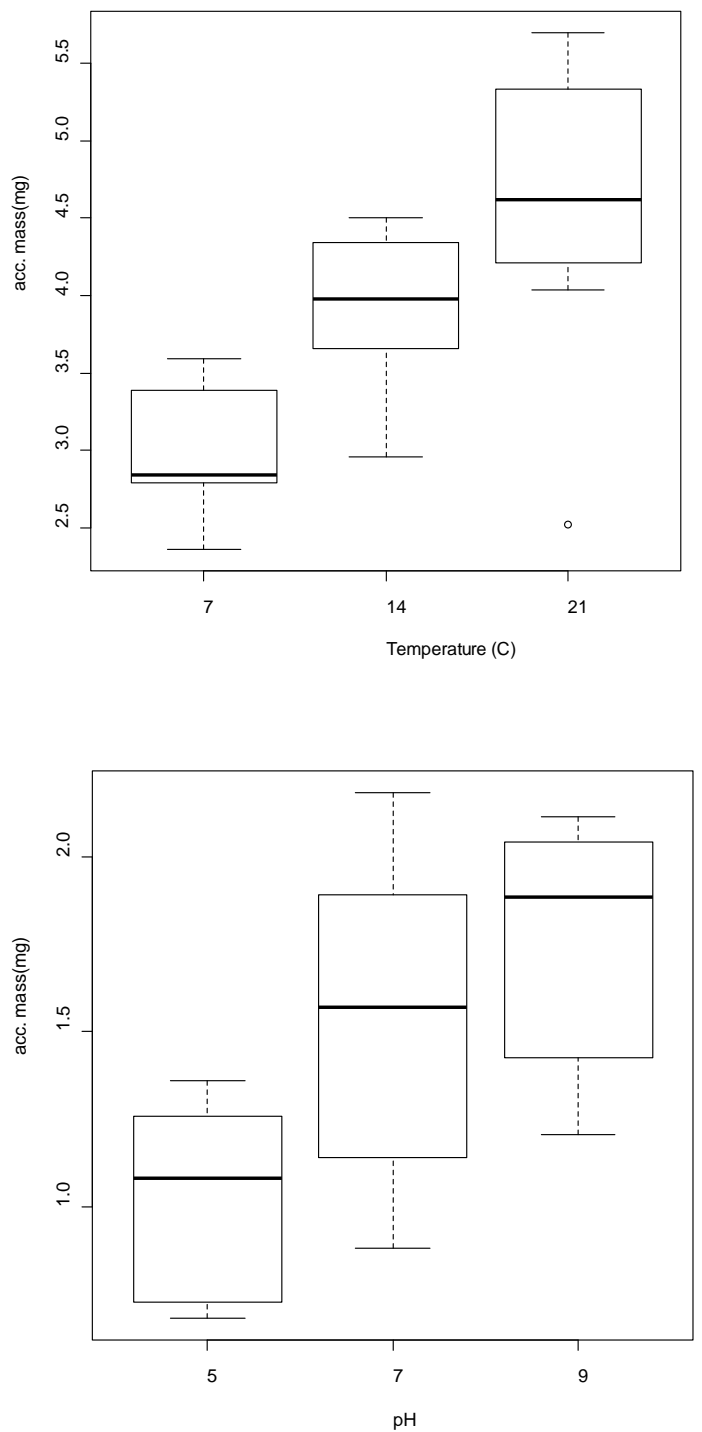

350 Figure 3. Boxplot and whiskers visualization of the analysis of variances in the parameter variation results, showing the variation due to temperature on nitrate uptake (top) and variation due to $\mathrm{pH}$ on phosphate uptake (bottom). 
Turbulence was found to have only a minor impact on sampling 355 rates, as expected from the relatively minor change in diffusion boundary layer (DBL) at lateral water velocities above $1 \mathrm{~cm} \mathrm{~s}^{-134}$.

The parameters of temperature, turbulence and $\mathrm{pH}$ were chosen based on previous experience with the Chemcatcher sampler ${ }^{29,} 30$. It should be noted that some variance remained unaccounted for 360 in this experiment and is represented as the residuals category.

This can be explained through methodological and analytical error, but there might also be other parameters/factors that influence the uptake characteristics for the sampler system that were not identified in the present study.

\section{Selectivity validation experiment}

The selectivity of the passive sampler in its current configuration was assessed by comparing results derived from the passive sampler to average concentrations obtained by ICP-MS (total phosphorous), the colorimetric method (Total nitrogen) and ion 370 chromatography $\left(\mathrm{NO}_{3}{ }^{-}\right.$and $\left.\mathrm{HPO}_{4}{ }^{2-}\right)$. Results showed that the passive sampler derived average concentration were in good agreement with the ionic species concentration analysed with the ion chromatography (see Figure 4).

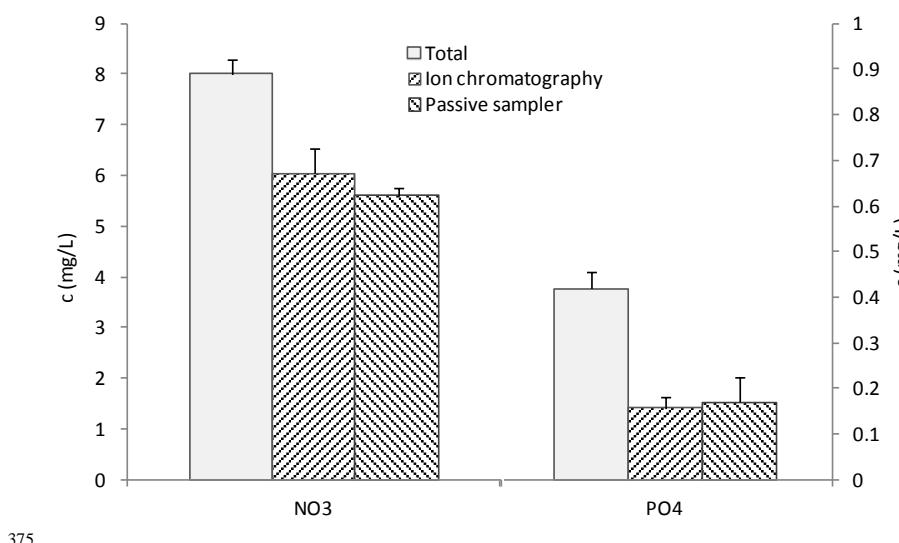

Figure 4. Concentration of total, ion chromatography and passive sampler derived results for nitrate/nitrogen and phosphate/phosphorous respectively. The $\mathrm{N}$-species values are shown on the left axis while the Pspecies are shown on the right axis.
380 This was in agreement with the assumption that the anionic exchange disk that acts as the receiving phase for the passive sampler binds favorably to the ionic species $\left(\mathrm{NO}_{3}{ }^{-}\right.$and $\left.\mathrm{HPO}_{4}{ }^{2-}\right)$ determined by the ion chromatographic method.

Furthermore, the visual biofouling in the laboratory experiments 385 were negligible, compared to the field deployment described below.

\section{Laboratory deployment}

The minimum deployment time was determined in the laboratory for two scenarios representing nutrient poor and nutrient rich 390 environments according to Swedish EPA guidelines for drinking water and a US EPA report on nutrients ${ }^{35}$. The concentrations in the two scenarios (nutrient poor and nutrient rich) were 0.1 and $10 \mathrm{mg} \mathrm{L}^{-1}$ nitrate and 0.006 and $0.048 \mathrm{mg} \mathrm{L}^{-1}$ phosphate, respectively. The minimum deployment times with regard to 395 analytical LOQ (defined as ten times the standard deviation of blanks) was 7 and 27 days for nitrate and phosphate, respectively in the nutrient poor case, while the time for the nutrient rich condition was $<1$ and 4 days.

\section{Field deployment}

400 The passive sampler was deployed at the local wastewater treatment plant to assess the applicability of the sampler to wastewater monitoring. Nitrate and phosphate concentrations were estimated using phosphorus loadings on the disks and the sampling rates obtained from the laboratory calibrations (Figure -405 ). Nitrate and phosphate concentrations were also analysed by the WWTP laboratory as part of the routine monitoring programme. The comparison between passive sampler and WWTP results should however be considered with caution owing to intrinsic differences between the methodologies. 

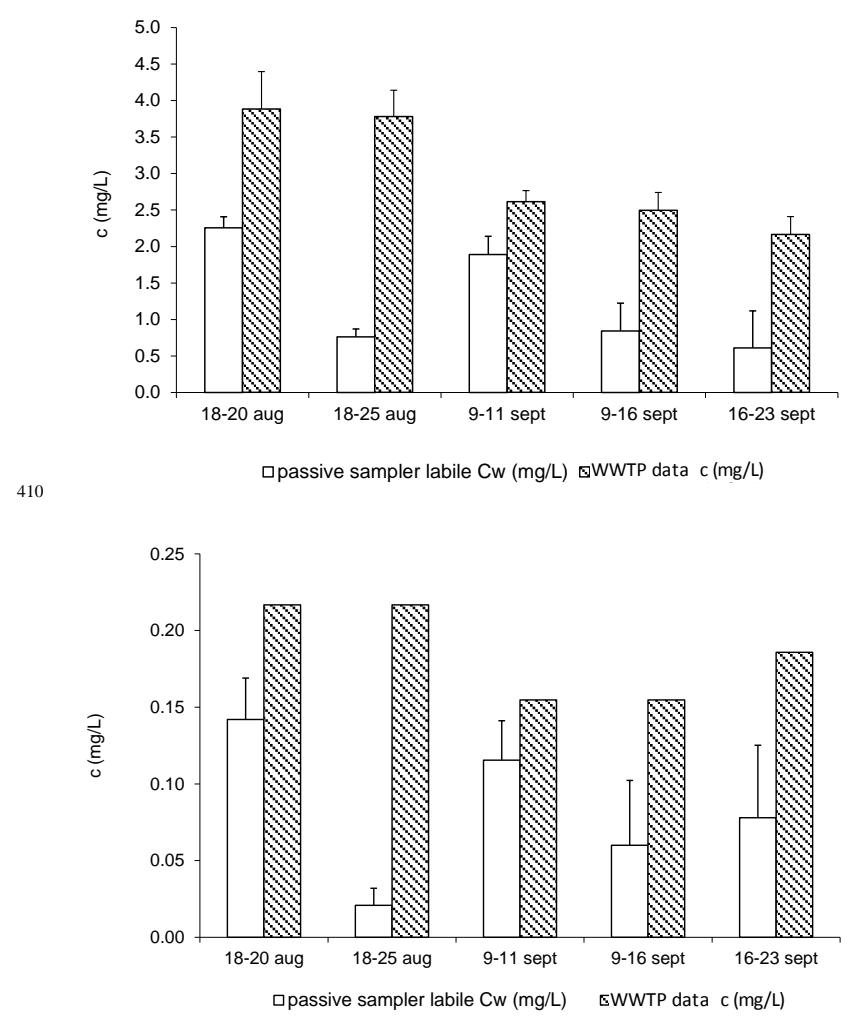

Figure 5. Comparison between passive sampler results and wastewater treatment plant (WWTP) provided data for nitrate (top) and phosphate (bottom). Three replicate samples and 95\% confidence level.

415 Passive sampler concentrations were consistently lower by some $55-90 \%$ than the corresponding results obtained from the WWTP laboratory (see Figure 5). Determination by the WWTP laboratory of nitrate and nitrite and phosphate were conducted on pooled samples daily and bi-weekly respectively. The 420 molybdenate reactive phosphorus method used at the WWTP is has been reported to overestimate measured phosphate levels owing to the integration of colloidal phosphorus in the measurements, in addition to phosphate $\left(\mathrm{HPO}_{4}{ }^{2-}+\mathrm{H}_{2} \mathrm{PO}_{4}{ }^{-}\right)^{36,37}$. The passive sampler system used in this study is assumed to ${ }_{425}$ selectively collect the dissolved ionic species of the analytes that diffuse through the limiting membrane and bind to the receiving phase. The selectiveness of the passive sampler can be partly explained by the discrepancy for phosphate between the passive sampler and the WWTP results. In addition, the method used for 430 nitrate analysis at the WWTP provides an aggregate of $\mathrm{NO}_{3}{ }^{-}$and $\mathrm{NO}_{2}{ }^{-}$, possibly resulting in an overestimation of nitrate results.

Despite these differences, it is possible to note that shorter exposures (3 days) yield values which are in closer agreement to WWTP data than the longer exposures (7 days). The shorter 435 exposure yielded passive sampler concentrations 65\% and 70\% lower than WWTP data , whereas for the longer exposure passive sampler concentrations were only $27 \%$ and $30 \%$ of WWTP data for nitrate and phosphate, respectively. Biofouling is a likely cause for this difference owing to the nutrient rich and 440 biologically active sample matrix. Biofouling has been reported to cause lower analyte uptake rates as biofilms present on the diffusion membrane surface compete for the labile nitrate and phosphate species ${ }^{38}$. Saturation of the receiving phase is a further problem in waters with high ionic strengths, but this was not 445 investigated further.

The passive sampler proved suitable for the monitoring of nitrate and phosphate concentrations in wastewater for short periods (3 days), but biofouling was found to reduce analyte uptake and affect the results for longer sampling periods. Ways to eliminate 450 the influence of biofouling by either inhibiting the biological growth on the disks or indirectly compensating for the lower results obtained ${ }^{15,39}$ need to be investigated.

\section{Conclusions}

Chemcatcher, a passive sampler previously used for the sampling 455 of metals and organic compounds in aqueous media, has been calibrated and tested for sampling labile nitrate and phosphate. An ion-exchange disk was used for analyte collection. Such a sampler provides the advantage of selectively collecting labile nitrate and phosphate species, as confirmed by comparison with 460 ion chromatography.

The passive sampler showed linear uptake characteristics, which permits calibration of the device for monitoring the timeaveraged concentration of nitrate and phosphate species. Laboratory deployments under different conditions showed that 465 temperature and $\mathrm{pH}$ conditions affect analyte uptake and have to be considered when calibrating and deploying the samplers. However, it remains to examine the performance of the device in high ionic strength solutions to see the effects of competative binding of other major anions to the receiving phase.

470 The potential application of the sampler to the monitoring of nitrate and phosphate in wastewater was assessed through a deployment at the local WWTP. Results from the passive sampler were found to be lower than concentrations obtained in the routine monitoring by the WWTP laboratory. The difference 475 might be explained by intrinsic differences between the methods.

For longer sampling periods ( $>3$ days), sampling was also found 
to be affected by biological growth on the disks, with the biofilm competing for the analytes and inhibiting diffusion to the sampler

38. Biofouldig could potentially be inhibited by the use of a 480 biocide $^{39}$ or additional membranes ${ }^{40}$ as demonstrated by other workers, but these options have to be investigated further.

Passive sampling is a promising technique for the monitoring of nitrate and phosphate in water. The method, which can be used for measuring time-averaged concentrations of nitrate and 485 phosphate, can support monitoring programmes and efforts to improve water quality, such as the EU Water Framework Directive. Further testing should be performed to ensure quality assurance and the issue of biofouling needs to be addressed for long-term sampling in nutrient rich environments.

\section{${ }_{490}$ Acknowledgements}

The authors of this article would like to thank the staff at GRYAB wastewater treatment plant for help with sampling and providing the data used for comparison.

\section{References}

495 1. R. G. Wetzel, Limnology. Second edition DOE/EV/01599-235-Pt.4; COO-1599-235-Pt.4; COO-1599-234; Other: ON: DE83016792 United StatesOther: ON: DE83016792Thu Feb 07 01:48:41 EST 2008NTIS, PC A99/MF A01; 1.ERA-08052224; EDB-83-170591English, 1983.

500 2. D. S. Baldwin, Water Research, 1998, 32, 2265-2270.

3. B. Vrana, I. J. Allan, R. Greenwood, G. A. Mills, E. Dominiak, K. Svensson, J. Knutsson and G. Morrison, TrAC, Trends in Analytical Chemistry, 2005, 24, 845-868.

4. B. Zabiegala, A. Kot-Wasik, M. Urbanowicz and J. NamieÅınik, $505 \quad$ Analytical and Bioanalytical Chemistry, 2010, 396, 273-296.

5. I. J. Allan, J. Knutsson, N. Guigues, G. A. Mills, A.-M. Fouillac and R. Greenwood, Journal of Environmental Monitoring, 2007, 9, 672-681.

6. T. Górecki and J. Namienik, TrAC - Trends in Analytical Chemistry, $510 \quad$ 2002, 21, 276-291.

7. I. J. Allan, B. Vrana, R. Greenwood, G. A. Mills, B. Roig and C. Gonzalez, Talanta, 2006, 69, 302-322.

8. I. J. Allan, K. Booij, A. Paschke, B. Vrana, G. A. Mills and R. Greenwood, Environmental Science and Technology, 2009, 515 43, 5383-5390.

9. I. J. Allan, B. Vrana, R. Greenwood, G. A. Mills, J. Knutsson, A. Holmberg, N. Guigues, A.-M. Fouillac and S. Laschi, TrAC Trends in Analytical Chemistry, 2006, 25, 704.

10. H. Zhang, W. Davison, R. Gadi and T. Kobayashi, Analytica Chimica 520 Acta, 1998, 370, 29-38.
11. J. G. Panther, P. R. Teasdale, W. W. Bennett, D. T. Welsh and H. Zhao, Environmental Science and Technology, 2010, 44, 9419-9424.

12. J. Rozemeijer, Y. Van Der Velde, H. De Jonge, F. Van Geer, H. P. Broers and M. Bierkens, Environmental Science and Technology, 2010, 44, 1353-1359.

13. R. M. Dils and A. L. Heathwaite, Water Research, 1998, 32, 14291436.

14. B. Müller, A. Stöckli, R. Stierli, E. Butscher and R. Gächter, Journal 530 of Environmental Monitoring, 2007, 9, 82-86.

15. C. Pichette, H. Zhang, W. Davison and S. Sauvé, Talanta, 2007, 72, 716-722.

16. S. Ding, D. Xu, Q. Sun, H. Yin and C. Zhang, Environmental Science and Technology, 2010, 44, 8169-8174.

535 17. L. Björklund Persson, G. M. P. Morrison, J. U. Friemann, J. Kingston, G. Mills and R. Greenwood, Journal of Environmental Monitoring, 2001, 3, 639-645.

18. B. Vrana, G. Mills, R. Greenwood, J. Knutsson, K. Svensson and G. Morrison, Journal of Environmental Monitoring, 2005, 7, 612

540 620

19. B. Vrana, G. A. Mills, P. E. G. Leonards, M. Kotterman, M. Weideborg, J. Hajlová, V. Kocourek, M. Tomaniová, J. Pulkrabová, M. Suchanová, K. Hájková, S. Herve, H. Ahkola and R. Greenwood, Journal of Environmental Monitoring, 2010, 12, 863-872.

20. K. Runeberg, Chalmers University of Technology, 2005.

21. S. Leaković, I. Mijatović, S. Cerjan-Stefanović and E. Hodžić, Water Research, 2000, 34, 185-190.

22. S. C. Chapra, Surface Water-Quality Modeling, Waveland Press, Incorporated, 2008.

23. P. J. Ross, Taguchi techniques for quality engineering: loss function, orthogonal experiments, parameter and tolerance design, McGraw-Hill, 1996.

24. W. Davison and H. Zhang, Nature (London, United Kingdom), 1994, 555 367, 546-548.

25. D. A. Alvarez, J. D. Petty, J. N. Huckins, T. L. Jones-Lepp, D. T. Getting, J. P. Goddard and S. E. Manahan, Environmental Toxicology and Chemistry, 2004, 23, 1640-1648.

26. J. K. Kingston, R. Greenwood, G. A. Mills, G. M. Morrison and L. B. $560 \quad$ Persson, Journal of Environmental Monitoring, 2000, 2, 487495.

27. S. L. Kaserzon, K. Kennedy, D. W. Hawker, N. Holling, B. I. Escher, K. Booij and J. F. Mueller, Chemosphere, 2011, 84, 497-503.

28. C. Picioreanu, M. C. M. van Loosdrecht and J. J. Heijnen, Water $565 \quad$ Science and Technology, 1997, 36, 147-156.

29. B. Vrana, G. A. Mills, E. Dominiak and R. Greenwood, Environmental Pollution, 2006, 142, 333-343.

30. B. Vrana, I. J. Allan, R. Greenwood, G. A. Mills, E. Dominiak, K. Svensson, J. Knutsson and G. Morrison, TrAC Trends in Analytical Chemistry, 2005, 24, 845-868.

31. C. Rivera, Chalmers, 2003.

32. K. Hornik, Editon edn., 2011. 
33. H. Zhang and W. Davison, Analytical Chemistry, 1995, 67, 33913400 .

575 34. O. A. Garmo, O. Royset, E. Steinnes and T. P. Flaten, Analytical Chemistry, 2003, 75, 3573-3580.

35. W. Environmental Protection Agency, DC. Office of Water., Ambient water quality criteria recommendations information supporting the development of state and tribal nutrient criteria $580 \quad$ EPA/822/B-01/011, Washington, D.C. , 2001.

36. A. Thomson-Bulldis and D. Karl, Limnology and Oceanography, 1998, 43, 1565-1577.

37. D. M. Karl and K. M. Björkman, Biogeochemistry of Marine Dissolved Organic Matter, 2002, 249-366.

585 38. P. A. Castillo, S. González-Martínez and I. Tejero, Editon edn., 1999, vol. 40, pp. 321-329.

39. L. Björklund Blom, G. M. Morrison, M. S. Roux, G. Mills and R. Greenwood, Journal of Environmental Monitoring, 2003, 5, 404-409.

590 40. E. Uher, H. Zhang, S. Santos, M. H. Tusseau-Vuillemin and C. Gourlay-Francé, Analytical Chemistry, 2012, 84, 3111-3118. 